www.jmscr.igmpublication.org

Impact Factor (SJIF): 6.379

Index Copernicus Value: 71.58

ISSN (e)-2347-176x ISSN (p) 2455-0450

crossref DOI: _https://dx.doi.org/10.18535/jmscr/v6i4.156

Journal Of Medical Science And Clinical Research

\title{
Functional Outcome of Talar Fracture Following Internal Fixation by using Cannulated Cancelous Screw: A Case Series Study
}

\author{
Authors \\ S. Abdul Ajees ${ }^{1}$, A. Sudharsan ${ }^{2}$ \\ ${ }^{1}$ Department of Orthopaedics, Government Rajaji Hospital, Madurai, Tamilnadu \\ ${ }^{2}$ Department of Orthopaedics, Thanjavur Medical College Hospital, Thanjavur, Tamilnadu
}

\begin{abstract}
Introduction: Talus fractures are commonly occur secondary to high energy mechanisms, management of the talus fracture in the multiply injured patient can be difficult. An important principle remains emergent reduction of dislocated joints whenever possible. Stabilization of the fractures and dislocations facilitates management of the soft tissues. However a good result for the talus fracture can still be seen, even when appropriate orthopaedic intervention is delayed due to multisystem injury.

Aim: To study about the functional outcome of talus fracture following internal fixation by using cannulated cancellous screws.

Materials \& Methods: Prospective evaluation of 17 patients in the age group of 15 years to 75 years with good general condition underwent open reduction and internal fixation with canulaed cancellous screw fixation for simple and compound fracture of talar body and talar neck up to compound grade II during August2014 to September 2016. The periodic evaluations were done clinically and radiologically at regular intervals. Post operatively patients were assessed using AORAS scoring system.

Results: Among the 17 patients 29.41 percent of patients had excellent Hawkin's functional outcome, 35.29 percent of patients had good outcome and 35.29 percent had fair outcome while none had poor outcome. The mean post op AOFAS score is 58.58 and mean follow up AOFAS score is 91.41.

Conclusion: In our study treatment of fracture talus with open reduction and screw fixation facilitated early mobilisation of the patients and helped achieving stable, pain free subtalar and ankle joints and preventing avascular necrosis of talus, subtalar and ankle joint arthritis. AOFAS score has significant improvement during follow up.

Keywords: talus, cannulated cancellous screw, avascular necrosis, subtalar arthritis.
\end{abstract}

\section{Introduction}

Major fractures and dislocations in the region of talus are uncommon. This may be due to the fact that it is rather deeply located, doesn't have tendon or muscle attachment and is strong. A consequence of this is that most reports on this type of injury have been based on relatively few cases on even those with a wide experience in accident surgery cannot claim to have treated more than a few isolated cases, that too handicapped by a lack of good radiographs in olden days. The largest series of talar injuries was reported by coltart ${ }^{1}$ (228 cases), the next being only 85 and 53 cases. This has meant a dearth of accurate description or classification in the medical literature and an absence of any real 
guidance on the treatment of injury to the talus. There are certain anatomical features of the talus that predispose it to complex injury, viz. 1) Sixty percent of the surface of it is cartilage and there are seven articular surfaces 2) It easily dislocates due to lack of muscle tendon attachments. 3) The talus is less important as the key stone of an arch than as the chief component of a universal joint in the foot, and is of medical importance. 4) Thinner cortex on medial side of bone as evidenced by histomorphometric analysis. 5) Extensive ligamentous attachments and important relations to tendon, blood vessels and nerves. Opinions vary widely as to the proper treatment and the history of fracture management reveals a continuous quest for improvement. In the past talectomy and below knee amputations were done for reducing the mortality from open and complex talar injuries. Later talectomy was opposed and early subtalar or peritalar fusion was suggested for irreducible fractures. Wrong opinion about the blood supply were held for a long time until 1952, when coltart described three groups of vessels supplying talus. Until the time when AVN was documented in arthrodesis for non trauma cases, early subtalar and triple arthrodesis were advocated in post trauma AVN cases, with a view to revascularise talus. Talus fractures are commonly associated with other musculoskeletal injuries and systemic trauma. Because the fractures occur secondary to high-energy mechanisms, management of the talus fracture in the multiply injured patient can be difficult. An important principle remains emergent reduction of dislocated joints whenever possible. Stabilization of the fractures and dislocations facilitates management of the soft tissues. However, in some cases the multisystem injury is so severe that treatment of the talus fracture is by necessity delayed. Nonetheless a good result for the talus fracture can still be seen, even when appropriate orthopedic intervention is delayed ${ }^{2}$. The cases that were treated in Madurai medical college over a period of 30 months were studied to find out the functional outcome of talar fractures treated with open reduction and internal fixation with cannulated cancelous screw fixation.

\section{Materials and Methods}

In the present study a prospective evaluation of 17 patients in the age range of 15 to 75 years with good general condition who underwent open reduction and internal fixation with cannulated cancelous screws. The study participants were recruited between august 2014 to September 2016 from the Department of Orthopaedics and Traumatology, Government Rajaji Hospital, Madurai, and Thanjavur Medical College Hospital, Tamilnadu, India. All the patients selected for study were examined according to protocol, associated injuries noted and clinical and lab investigations carried out in order to get fitness for surgery. Consent of the patient taken for surgery. Patients were followed till Union was achieved clinically as well as radiologically.

\section{Inclusion Criteria}

- Simple and compound fracture of talar body and talar neck up to compound Gr II,

- Patient age from 15 to 75 years and both sexes.

\section{Exclusion Criteria}

- Comorbid conditions not permitting major surgical procedures

- Patients compound Gr III A, B, C Talar Fractures

- Delayed presentations

- Poor skin conditions.

Patients underwent a pre-operative evaluation including the following parameters: $\mathrm{Hb}$, blood sugar, Renal function test, X-ray - AP, LAT, and CT scan- ankle with foot. Classification of fracture was done. Initially below knee slab with adequate padding was performed. The time interval between injury and surgery was 7 to 11 days. All the cases underwent spinal anaesthesia and the following implants and instruments were used cannulated cancelous screws $4 \mathrm{~mm}$, cannulated screw system, K- wire, osteotome and mallet. Intra operative data recorded in the profoma. After postoperative protocol suture 
removal on twelfth post op day below knee cast applied with ankle in neutral position. After completing the hospital treatment patients were discharged and called for regular follow up at 1,3,6,12 and 18 months. All the patients have been clinically assessed by Hawking's grading and AOFAS scoring system at 3 months interval. Radiological assessment for progression and time of union, fracture alignment and implant related complications have been analyzed. Data collected at the end of the study was statistically analyzed.

\section{Surgical Procedure}

In this study we have used anteromedial (8 cases), anteromedial and posterolateral combined (4), and anteromedial and anterolateral combined (5) approaches for internal fixation. Under $\mathrm{C}$-arm guidance, locate the interdigitating fracture lines medially or laterally for a guide to reduction, even if a gap remains in the opposite cortex. Beginning just posterior to the articular surface of the head on the medial or lateral aspect of the neck, drill two or three small $\mathrm{K}$ wires through the neck and into the body to hold the reduction. Depending on the available space for fixation, a $4.0-\mathrm{mm}, 4.5$ $\mathrm{mm}$, or $6.5-\mathrm{mm}$ partially threaded cannulated screw can be used. In each case, care must be taken to countersink the screw head to provide a flat area for seating of the screw head.

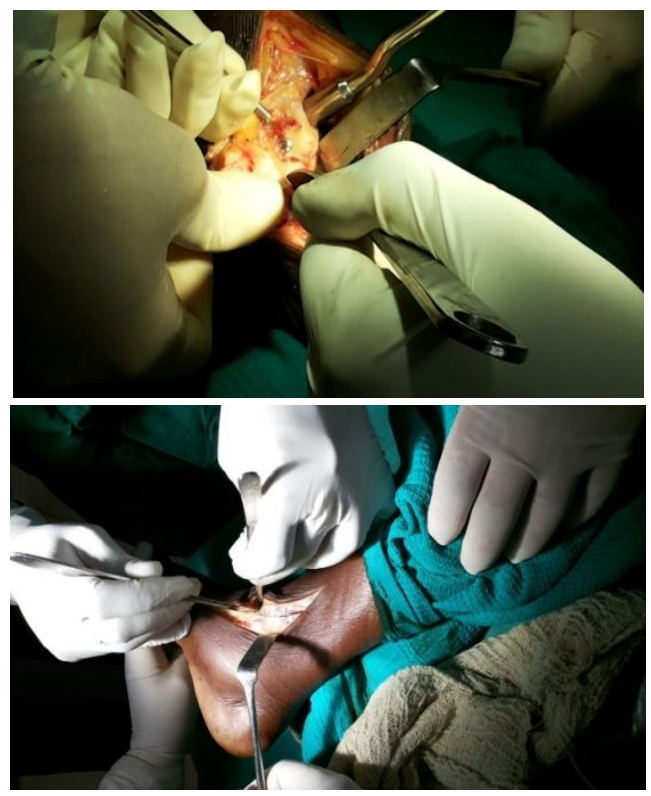

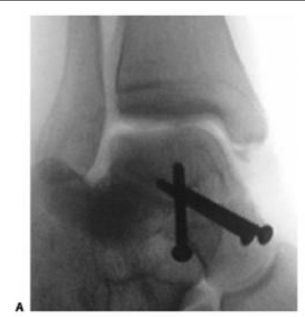
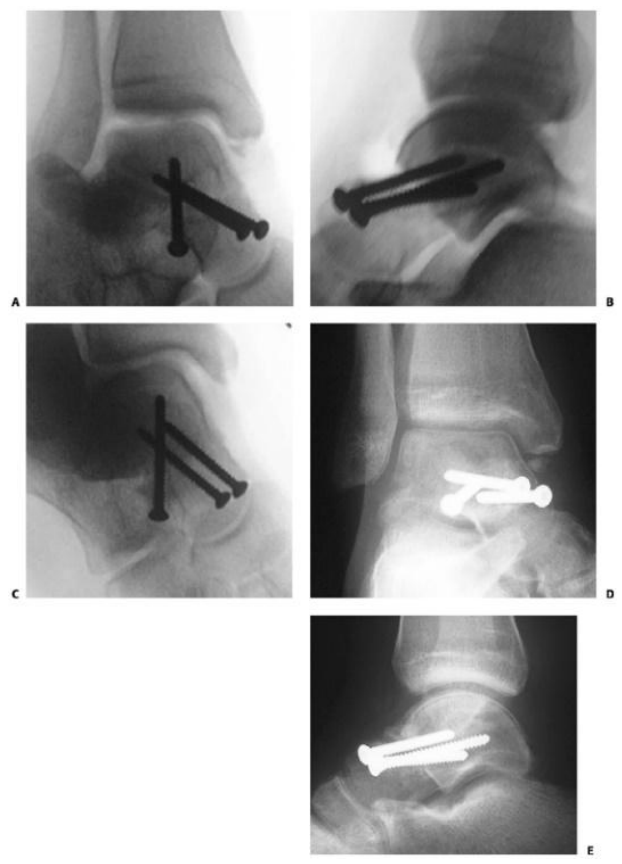

\section{Results}

All the seventeen patients in our study were treated with internal fixation with cannulated cancelous screws. The longest follow up period was 20 months and shortest follow up period was 9 months, mean follow up period was 14 months. Follow up analysis was made using AOFAS scoring and Hawkins grading criteria. In our study, $58.8 \%$ of patients were less than 30 years of age. $82.4 \%$ of patients were male and there was no significant difference in the side affected (right-8, left-9). Most of the patients sustained injury by fall from height (52.9\%). 58.8\% of patients had fracture of neck of talus among others. In this study, $29.41 \%$ of patients had excellent outcome, $35.29 \%$ patients had good outcome and $35.29 \%$ had fair outcome, while none had poor outcome. In this study, only 1 patient developed screw prominence and wound infection, treated with IV antibiotics, and screw removal done. One patient developed avascular necrosis of the talus and one another developed subtalar arthritis, both of them were treated with subtalar arthrodesis. 
JMSCR Vol||06||Issue||04||Page 948-956||April
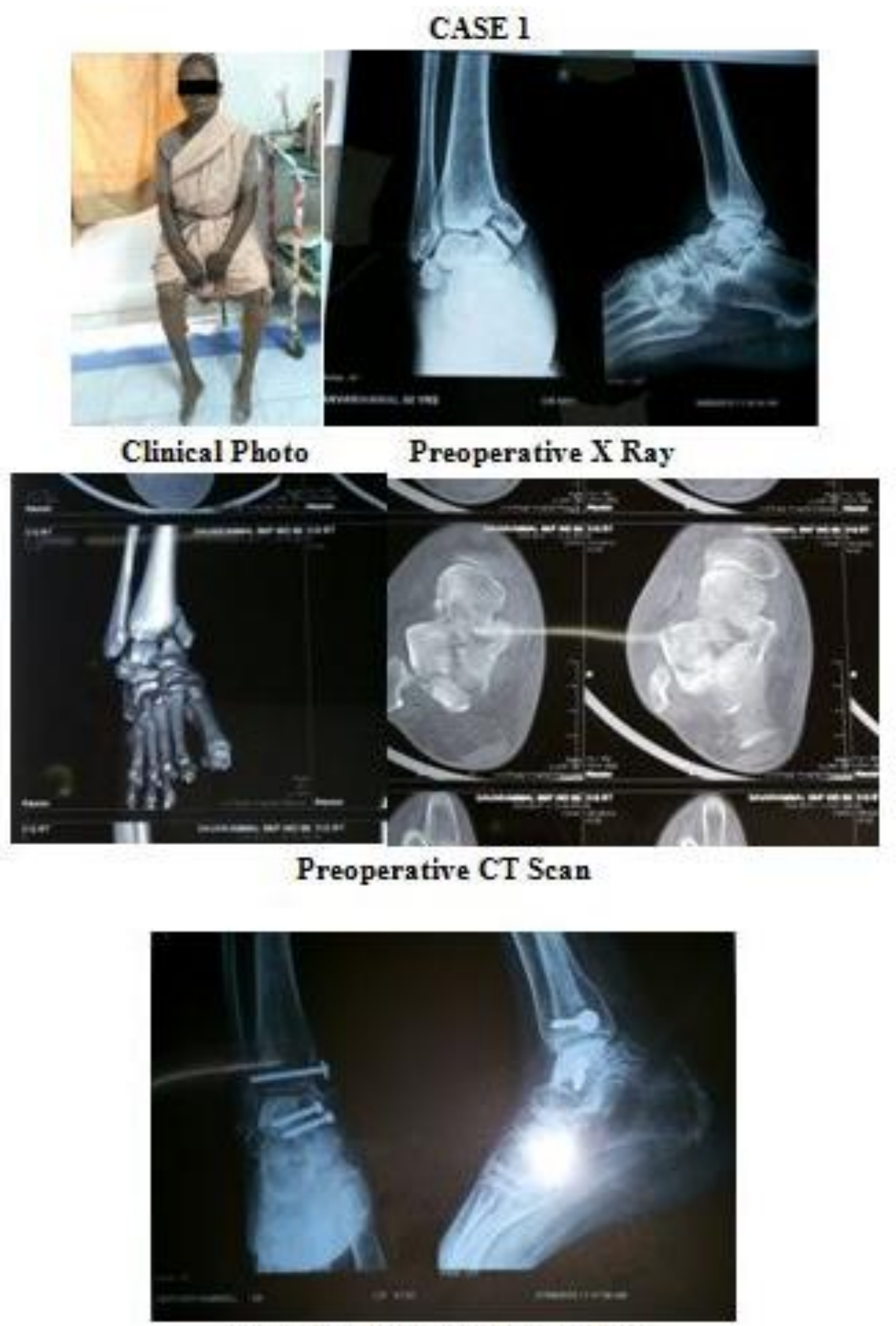

Immedite Postoperative X-Ray 

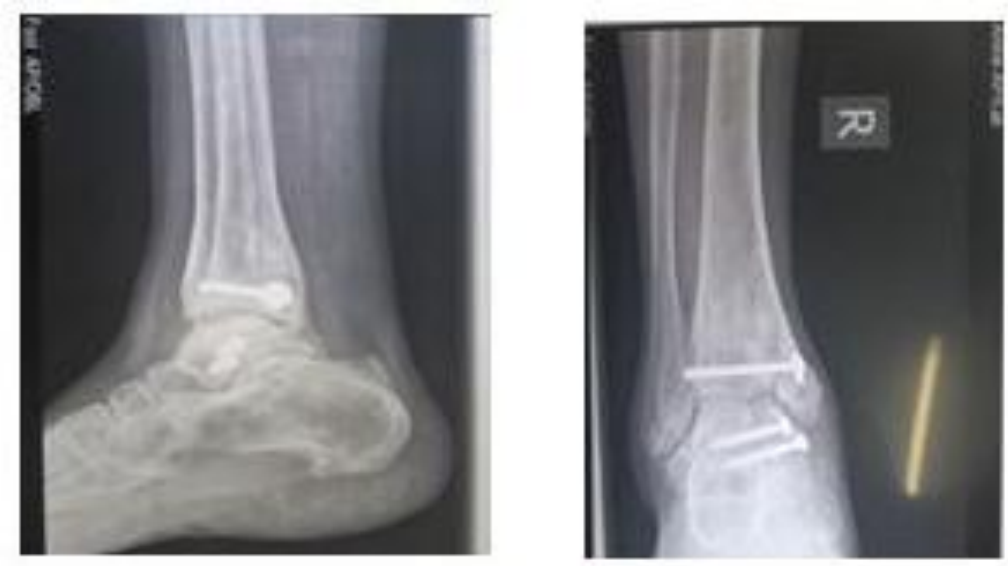

1 Year Follow Up X-Ray

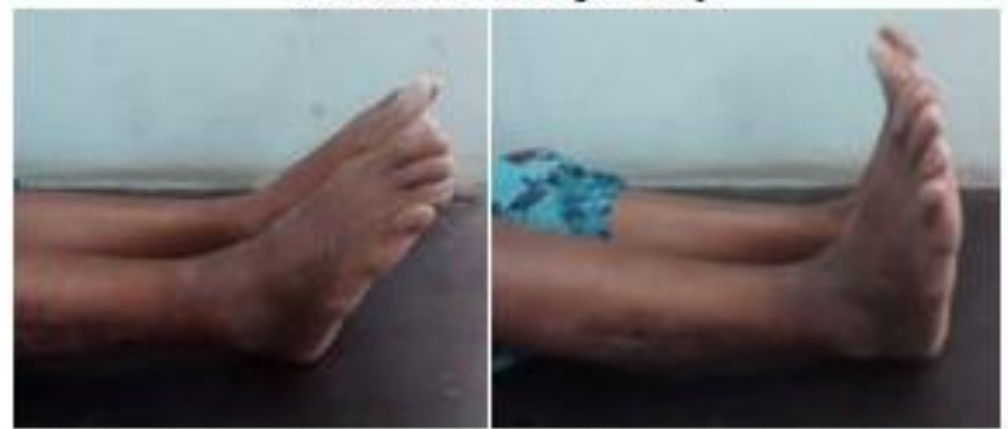

ROM: Plantar Flexion (0 To 35 Degree) DorsiFlexion (0 To 15 Degree. Minimal Stiffness Present.

Case 2 Hawking's Grading Results: Excellent

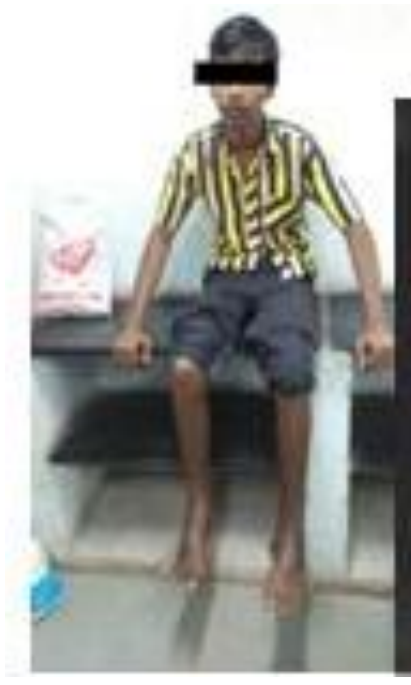

Clinical Picture

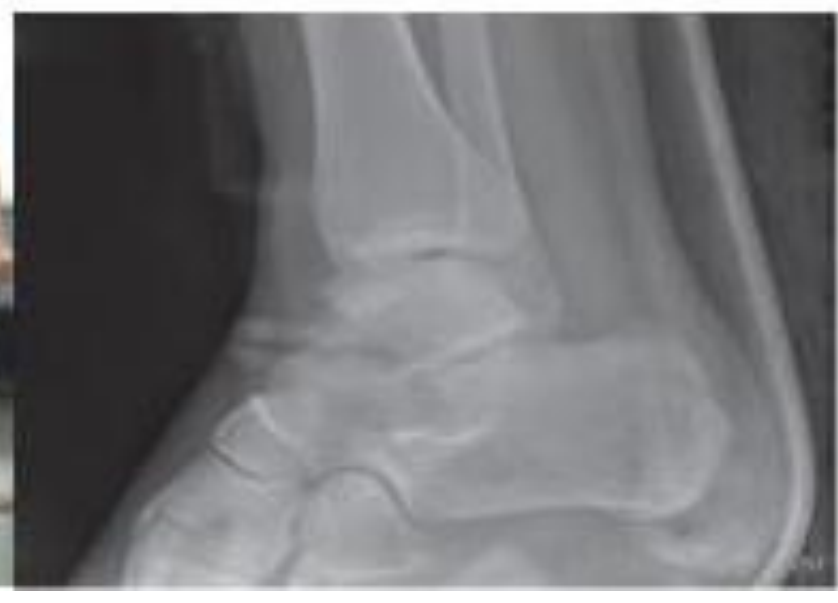

Preoperative X-Ray 


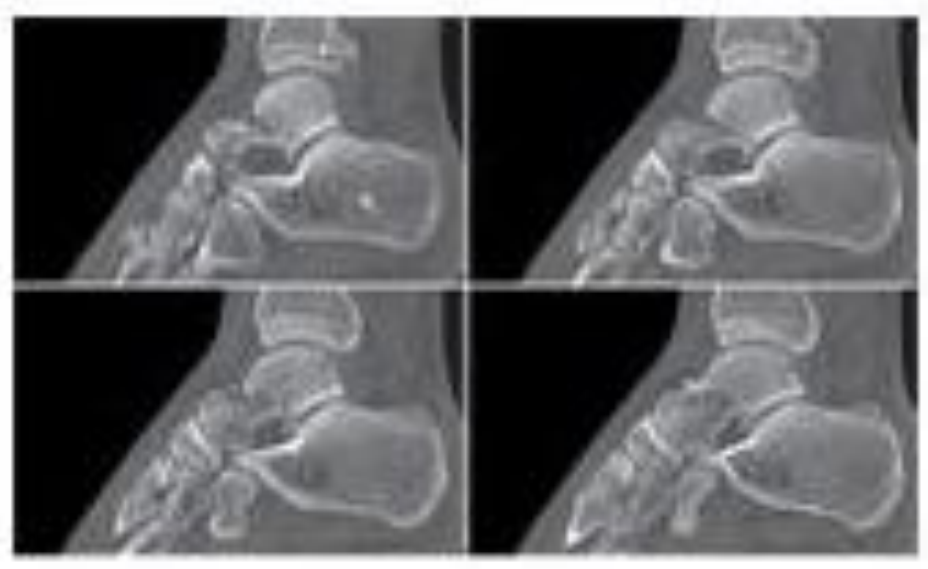

Preoperative CT Scan

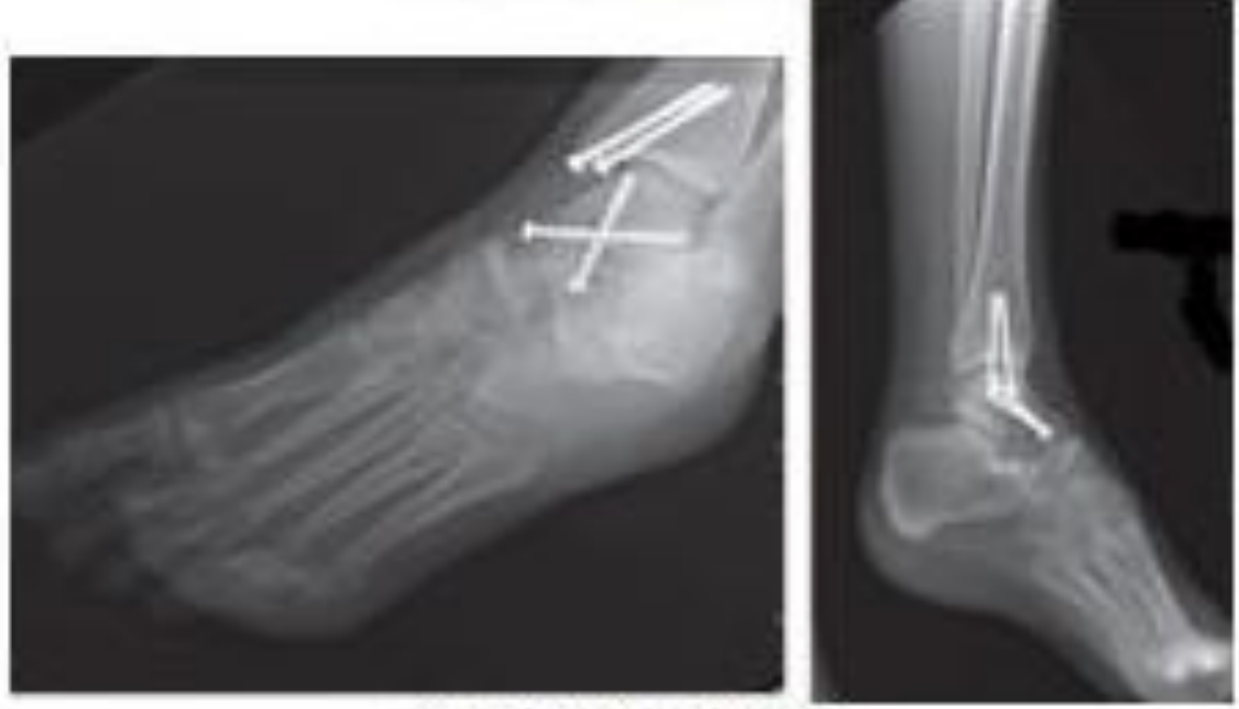

Poatoperative X-Ray

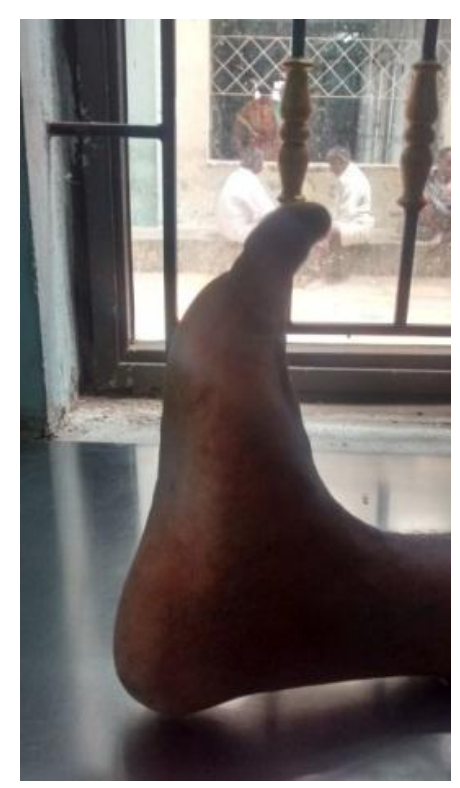

ROM: Dorsiflexion (0 to 15 degree)

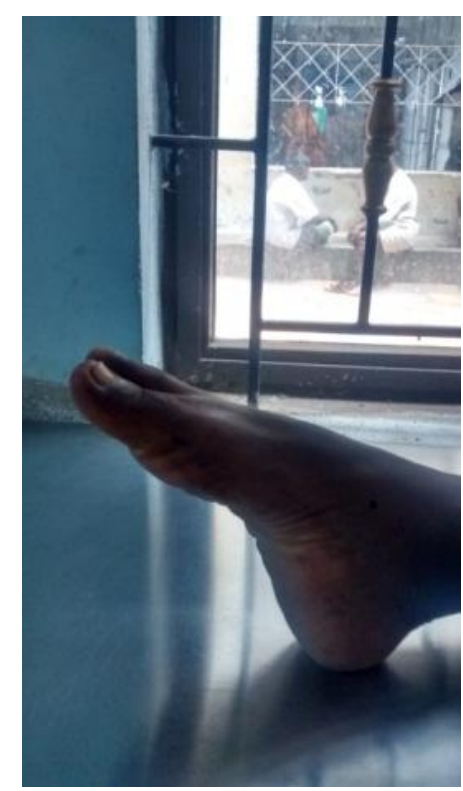

Plantar flexion (0 to 40 degree) 
Table - 1 Site of Fracture

\begin{tabular}{|l|c|c|}
\hline Site of Fracture & No. of Cases & \% \\
\hline Head & 2 & 11.8 \\
\hline Neck & 10 & 58.8 \\
\hline Body & 5 & 29.4 \\
\hline Total & 17 & 100.0 \\
\hline
\end{tabular}

Table - 2 Associated Injury

\begin{tabular}{|l|c|c|}
\hline Associated Injury & No. of Cases & \% \\
\hline Medial malleolus fracture & 3 & 17.7 \\
\hline Bimalleolar fracture & 1 & 5.9 \\
\hline Calcaneal fracture & 2 & 11.8 \\
\hline L2 burst \# incomplete neurological deficit & 1 & 5.9 \\
\hline Nil & 10 & 58.8 \\
\hline Total & 17 & 100.0 \\
\hline
\end{tabular}

Table - 3 Comparisons of AOFAS

Pre OP vs Post OP Mean Score

\begin{tabular}{|l|c|c|c|}
\hline AOFAS SCORE & Mean & SD & 'p' value \\
\hline PREOP SCORE & 27.118 & 3.97 & \\
\hline POSTOP SCORE & 58.588 & 4.08 & $<0.001$ \\
\hline
\end{tabular}

Table - 4 Comparison of AOFAS Score

Post OP vs Follow Up Mean

\begin{tabular}{|l|c|c|c|}
\hline AOFAS SCORE & Mean & SD & 'p' value \\
\hline Post OP Score & 58.588 & 4.08 & \\
\hline Follow up Score & 91.412 & 4.45 & $<0.001$ \\
\hline
\end{tabular}

Table - 5 Hawkin's Functional outcome Grading Results

\begin{tabular}{|l|c|c|}
\hline Hawkin's Grading Results & No. of Cases & \% \\
\hline Excellent & 5 & 29.41 \\
\hline Good & 6 & 35.29 \\
\hline Fair & 6 & 35.29 \\
\hline Poor & 0 & 0.00 \\
\hline Total & 17 & 100.00 \\
\hline
\end{tabular}

\section{Discussion}

Fractures involving talus are rare in orthopaedic practice. The role of the talus in lower extremity function, the complexity of the anatomy, and the variability of fracture patterns often complicate treatment of talar fractures and often frustrate orthopaedic surgeon. The primary goal of treatment is to obtain stable, pain free subtalar and ankle joints and restoration of their maximum function. Mean age group of our study (32.9\%) is agreeable with most of the other studies, Canale and Kelley ${ }^{3}$ (30 years), Sneppens et al (38 years), Comfort $^{6}\left(25\right.$ years), Kenwright and Taylor ${ }^{7}(35$ years). Though the inclination is towards younger age, this study like others, showed a wide age range of patients (18 to 63).The present study showed that the ratio of the male and female patients (14:3) is significantly more towards the former which is similar to most other studies, Comfort (16:5), Sneppens et al (15:5), Kenwright and Taylor(49:9). The high incidence in males in younger age, a period of active physical life can be attributed to more exposure to the injuries. Most of the studies series (Lorentzen ${ }^{8}$, Comfort, Sneppens et al, Mindal ${ }^{9}$ et al) recorded fall from height being the largest group in the patient population (39 to 58\%) with talar injuries, followed by fall of heavy weight, RTA, twisting injuries, etc. in our study, fall from height was the most common mode of injury $(52.9 \%)$. In our 
study, there was more or less equal side distribution (Right-8, Left-9), which is comparable with that reported by Sneppens et al(right-11 left-10).In our study, the incidence of fractures in various parts of talus was comparable with that of others.

\begin{tabular}{|l|c|c|c|}
\hline SITE & OUR STUDY & ADELAAR et al & COLTART et al $^{\mathbf{1}}$ \\
\hline Head & $11.8 \%$ & $5-10 \%$ & $2.6 \%$ \\
\hline Neck & $58.8 \%$ & $50 \%$ & $47 \%$ \\
\hline Body & $29.4 \%$ & $15-20 \%$ & $9.6 \%$ \\
\hline
\end{tabular}

In our study, associated injuries, medial malleolus $(17.7 \%)$, bimalleolar $(5.9 \%)$, calcaneal fractures $(11.8 \%)$, is comparable with Canale and Kelly series(medial malleolus-14\% calcaneum-9\%). Among the Hawkins classification of fracture neck of talus, type II (60\%), was found to be more common, similar to other studies, kanale's (type II-42\% typeIII-32\%), Pantazopoulus ${ }^{11}$ (45\% type II, $30 \%$ type III). In our study, $29.4 \%$ of the injuries were compound and $70.6 \%$ were simple, comparable with that of Rudolf's(simple 63\%) and Komalf et al(simple 70\%).In our study, we encountered a complication in case 3 of master chart, screw prominence and mild infection. It was treated with screw removal and antibiotics. Similar complication had been encountered before as in Canale's series (7\%).Another complication encountered during our study was avascular necrosis of the talus(case 7 of master chart), for which subtalar arthrodesis was performed. Avascular necrosis, in past studies had been common, following fracture dislocation of the talar neck, Coltart (25\%), Hawkins ${ }^{12}(58 \%)$, Lorentzen(21\%). One patient in our study developed arthritis following open reduction and screw fixation. Subtalar arthrodesis was performed, followed by early mobilisation, limb elevation and use of proteolytic enzymes per orally. Coltart had reported 50\% of subtalararthrosis and 5\% of ankle arthrosis in his study. Inspite of such complications associated with these fractures, and their management using this technique, according to American orthopaedic foot and ankle society (AOFAS) score, we achieved a score of 91 or above for 12 cases. Hawkin's functional outcome grading was: excellent (5 cases-30\%), good(6 cases-35\%), fair (6cases-35\%) results and none of them had poor results.

\section{Conclusion}

In this study treatment of fracture talus with open reduction and screw fixation facilitated early mobilisation of the patients and helped achieving stable, pain free subtalar and ankle joints and preventing avascular necrosis of talus, subtalar and ankle joint arthritis. AOFAS score has significant improvement during follow up. The screw can be fixed either anterior to posterior direction or from posterior to anterior direction. But posterior to anterior directed screws are biomechanically stronger. We faced some complications like screw prominence and wound infection on appropriate treatment these complications subsides on later date. One patient developed avascular necrosis of the talus and one another developed subtalar arthritis, both of them were treated with subtalararthrodesis. Though age and sex of the patient, type of fracture, time of presentation, amount of blood loss, time of union influences the functional outcome, these parameters shows no gross variations in all patients regarding outcome and showed good results.

\section{References}

1. Coltart, W. D. (1952) Aviatorsastragalus. I. Bone Jt Surg. 34-B, 545-566.

2. Sanders D.W. Talus fractures. In: Rockwood C.A., Green D.P., editors. Fractures in adults. Lippincott Williams \& Wilkins; Piladelphia: 2010. pp. 2022-2063.

3. Canale S.T., Kelly F.B., Jr. Fractures of the neck of the talus long-term evaluation of 
seventy-one cases. J Bone Joint Surg Am. 1978;60(2):143-156.

4. Canale, ST, Belding, RH: Osteochondral lesions of the talus. J. Bone Joint Surg. 62A: 97-102, 1980

5. O. Sneppen, S. Bach Christensen, O. Krogsøe $\&$ J. Lorentzen (1977) Fracture of the Body of the Talus, Acta Orthopaedica Scandinavica, 48:3, 317-324,

DOI: $10.3109 / 17453677708988775$

6. Comfort TH, Behrens F, Gaither DW, Denis F, Sigmond M. Long-term results of displaced talar neck fractures. ClinOrthopRelat Res 199:81-87, 1985

7. Kenwright J, Taylor RG. Major injuries of the talus. J Bone Joint Surg Br 1970;52(1):36-48.

8. J. E. Lorentzen, S. Bach Christensen, O. Krogsøe \& O. Sneppen (1977) Fractures of the neck of the talus, Acta Orthopaedica Scandinavica, 48:1, 115-120, DOI: 10.3109/17453677708985121

9. Mindell, E. H., Cisek, E. E., Kartalian, G. CY: Dziob, J. M. (1963) Late results of injuries to the talus. J. Bone Jt Surg. 45-A, 221--245.

10. Adelaar R.S. The treatment of complex fractures of the talus. OrthopClin N Am. 1989;20(4):691-707.

11. h.Pantazopoulos, Th., Galanos, P., Vayanos, E., Mitson, A. \&Hartofilakidis-Garofalitis, G. (1974) Fractures of the neck of the talus. Actaorthop. scand. 45, 296-306

12. Hawkins L.G. Fractures of the neck of the talus. J Bone Joint Surg Am. 1970;52(5):9911002 . 